\title{
Effect of Orange Oil on the Oral Absorption of Enrofloxacin in Rats
}

\author{
Jong-Hwan LIM ${ }^{1)}$, Myoung-Seok KIM ${ }^{2)}$, Youn-Hwan $\mathrm{HWANG}^{3)}$, \\ In-Bae $\mathrm{SONG}^{3)}$, Tae-Won $\mathrm{KIM}^{3)}$, and Hyo-In YUN ${ }^{3)}$ \\ ${ }^{1)}$ B\&C Biopharm, Suwon, Gyeonggi 443-759, ${ }^{2)}$ Jeollanamdo Development Institute for Traditional \\ Korean Medicine, Jangheung, Jeollanam 529-851, and ${ }^{3)}$ Laboratory of Veterinary Pharmacology \\ and Toxicology, College of Veterinary Medicine, Chungnam National University, \\ Daejeon 305-764, South Korea
}

\begin{abstract}
This study was conducted to evaluate the oral absorption of enrofloxacin (ENFX) in rats when administered with orange oil or its main component, limonene. Compared with the group administered ENFX alone, the ENFX + limonene group did not show any significant difference in the absorption of ENFX, whereas the extent and rate of absorption of ENFX were significantly decreased in the ENFX + orange oil group $\left(C_{\max },-43 \% ; T_{\max }, 129 \%\right)$. In addition, $t_{1 / 2 \lambda z}$ and MRT of ENFX were prolonged by the concomitant administration of orange oil. The AUCs of ENFX were not affected in the ENFX + orange oil group. These results suggest that decreased oral absorption could reduce the efficacy of ENFX therapy in animals.
\end{abstract}

Key words: enrofloxacin, limonene, orange oil

Enrofloxacin (ENFX), a member of a secondgeneration group of nalidixic acid derivatives, is widely used for indications of gastro-intestinal, respiratory and urinary tract infections against gram-negative and grampositive bacterial infection in veterinary medicine [27]. It is metabolized to ciprofloxacin via de-ethylation of the ethyl group on the piperazine ring [24] and mainly excreted as a parent drug and its metabolite by glomerular filtration and tubular excretion $[15,26]$.

ENFX is mainly found as a zwitterion, which is one of the electrically neutral forms of the molecule but which also behaves as an anionic and cationic form [27]. These properties allow ENFX to cross physiological barriers by passive diffusion and also use active transport mechanisms such as anionic and/or cation transporters
$[4,5,18]$. In addition, recent studies have shown that fluoroquinolones are substrates of efflux transporters belonging to the ATP-binding cassette (ABC) group, such as P-glycoprotein (P-gp/MDR1/ABCB1), multidrug resistance-associated protein 1 or 2 (MRP1 or MRP2) and the breast cancer resistance protein (BCRP/ABCG2), as well as influx transporters including organic anion transporting polypeptide (OATP) family [3, 12, 22, 23].

The oral absorption of a compound is dependent on several factors including the characteristics of the compound (e.g., solubility and lipophilicity), as well as its interaction with the intestinal epithelium. Drug interaction between drugs and fruit juice has been widely reported. Many studies have reported that grapefruit

(Received 14 July 2011 / Accepted 24 August 2011)

Address corresponding: H.-I. Yun, Laboratory of Veterinary Pharmacology and Toxicology, College of Veterinary Medicine, Chungnam National University, Gung-dong, Yuseong-gu, Daejeon 305-764, South Korea 
juice and orange juice is able to inhibit P-gp [3, 6, 8, 10, 19]. Moreover, crude drugs or natural herbs containing various terpenoids and flavonoids can be considered to affect the bioavailability of concomitant P-gp substrates or OATP inhibitors after oral administration [29].

Orange oils are complex mixtures containing numerous volatile compounds, mostly terpenes and oxygencontaining terpene structures, as well as oxygencontaining compounds. The major component in orange oils is limonene, which account for approximately $95 \%$ of the oil mass $[8,21]$. Orange oil is widely used by the food and pharmaceutical industries as a source of flavor, natural preservatives and fragrance. However, orange oil-drug interaction is still not completely understood. The objective of the present study was to examine the effect of orange oil and its main component, limonene, on the oral absorption of ENFX in rats.

ENFX as analytical standard was purchased from Sigma (St. Louis, MO, USA) and its oral solution (Baytril ${ }^{\circledR} 0.5 \%$ oral solution, Lot. $2131 \mathrm{H}$, Bayer Korea, Ansan, Korea) was provided from a local distributor. HPLC grade methanol and acetonitrile were purchased from Mallinckrodt Baker (Phillipsburg, NJ, USA). Coldpressed orange (Citrus sinensis) oil was obtained commercially available product from commercial source (Cakesoap, Daegu, Korea). In the analysis of volatile components using gas chromatography/mass spectrometry (GC/MS), limonene was the principle volatile component $(92.13 \%)$ of the essential oil and other predominant components were $\beta$-myrcene $(1.92 \%), \gamma$-terpinene $(1.21 \%)$, linalool $(0.92 \%)$ and $\alpha$-pinene $(0.76 \%)$. Limonene and other chemicals were reagent grade and obtained from Sigma (St. Louis, MO, USA).

A pharmacokinetic study of ENFX was conducted with healthy male 8-week-old Sprague-Dawley rats (NTac:SD) weighing from 250 to $300 \mathrm{~g}$. They were purchased from Samtaco BioKorea (Osan, Korea) and acclimated for one week before use. The room temperature, humidity, and light cycles were controlled to $23 \pm 2{ }^{\circ} \mathrm{C}, 55 \pm 3 \%$, and a 12 -h light-dark cycle. Animals were fed pelleted feed concentrate with free access to food and water. They did not receive any drug treatment before the study. The experimental protocols were approved by the Institutional Animal Care and Use Committee of Chungnam National University
(Registration No. 2009-1-15, Daejeon, Korea).

The pharmacokinetics of ENFX were investigated following a single dose of $10 \mathrm{mg} / \mathrm{kg}$ given orally by gavage with water, limonene or orange oil ( $\mathrm{n}=6$ each). The administered volume was $5 \mathrm{ml} / \mathrm{kg}$, and the dosing solution consisted of ENFX oral solution and water or $10 \%$ of limonene or orange oil $(40: 60, \mathrm{v} / \mathrm{v})$. Blood samples were taken from the tail vein at 0 (pre-), 0.25 , $0.5,1,2,4,6$ and $8 \mathrm{~h}$ following treatments. Approximately $0.05 \mathrm{ml}$ of blood was collected in heparinized microcontainers, and plasma was obtained by centrifugation. Plasma samples were stored at $-70^{\circ} \mathrm{C}$ until analysis. This study was approved by the Animal Care Committee of Chungnam National University and was conducted at the Research Institute of Veterinary Medicine (Daejeon, Korea).

ENFX concentrations in plasma were determined by modified method described by Tyczkowska et al. using high-performance liquid chromatography/mass spectrometry [24]. The limit of quantitation of ENFX was $0.01 \mu \mathrm{g} / \mathrm{ml}$. The inter-day and intra-day precision $(\mathrm{CV}, \%)$ for ENFX were below $15 \%$ and the calibration curve showed a good linearity $(r>0.99)$ from 0.01 to 5 $\mu \mathrm{g} / \mathrm{ml}$.

The pharmacokinetic analysis was performed by the one compartmental analysis using a combined linear trapezoidal rule approach (WinNonlin 5.2, Pharsight, St. Louis, MO, USA). Peak plasma concentrations $\left(\mathrm{C}_{\max }\right)$ of the drug and times to reach the peak concentration $\left(t_{\max }\right)$ were determined from the individual plasma concentration-time curves. Lambda $\mathrm{z}\left(\lambda_{\mathrm{z}}\right)$ is a first-order rate constant associated with the terminal (log linear) segment of the curve. It was estimated by the linear regression of the terminal data points. The terminal elimination half-life $\left(\mathrm{t}_{1 / 2 \lambda_{z}}\right)$ was calculated by $\mathrm{t}_{1 / 2 \lambda_{z}}=0.693 /$ $\lambda_{\mathrm{z}}$. The area under the plasma concentration-time curves (AUC) was calculated by the method of trapezoids. The area under the first moment curve (AUMC) was calculated as the product of time and drug concentration-time. Mean residence time (MRT) was calculated from MRT $=$ AUC/AUMC. Absorption rate constant $\left(k_{\mathrm{a}}\right)$ was estimated from the absorption phase by compartmental modeling. The mean absorption time (MAT) of ENFX was calculated using the equation $\mathrm{MAT}=1 / k_{a}$.

Data are shown as means \pm standard error (SE), and 
Table 1. Pharmacokinetic parameters after a single oral administration of $10 \mathrm{mg} / \mathrm{kg}$ of ENFX with coadministration of water, limonene or orange oil to rats

\begin{tabular}{lccc}
\hline $\begin{array}{l}\text { Pharmacokinetic } \\
\text { parameters (Unit) }\end{array}$ & Water + ENFX & Limonene + ENFX & Orange oil + ENFX \\
\hline $\mathrm{C}_{\max }(\mu \mathrm{g} / \mathrm{ml})$ & $1.78 \pm 0.13$ & $1.49 \pm 0.20$ & $1.01 \pm 0.03^{\text {a) }}$ \\
$\mathrm{T}_{\max }(\mathrm{h})$ & $0.58 \pm 0.08$ & $0.88 \pm 0.12$ & $1.33 \pm 0.23^{\text {a) }}$ \\
$\mathrm{AUC}_{0 \rightarrow \infty}(\mathrm{h} \cdot \mu \mathrm{g} / \mathrm{ml})$ & $5.33 \pm 0.34$ & $5.48 \pm 0.13$ & $5.51 \pm 1.01$ \\
$\mathrm{~V} / \mathrm{F}(1 / \mathrm{kg})$ & $6.59 \pm 0.48$ & $7.50 \pm 0.92$ & $9.74 \pm 0.77^{\text {a) }}$ \\
$\mathrm{Cl} / \mathrm{F}(1 / \mathrm{kg})$ & $2.09 \pm 0.21$ & $1.81 \pm 0.03$ & $1.72 \pm 0.07^{\text {a) }}$ \\
$\mathrm{t}_{1 / 2 \lambda z}(\mathrm{~h})$ & $2.23 \pm 0.11$ & $2.89 \pm 0.37$ & $3.90 \pm 0.18^{\text {a) }}$ \\
$\mathrm{MAT}(\mathrm{h})$ & $0.22 \pm 0.04$ & $0.54 \pm 0.05^{\text {a) }}$ & $0.71 \pm 0.12^{\text {a) }}$ \\
MRT $(\mathrm{h})$ & $3.21 \pm 0.19$ & $4.48 \pm 0.59$ & $6.20 \pm 0.22^{\text {a) }}$ \\
\hline
\end{tabular}

${ }^{*} \mathrm{C}_{\max }$, the peak or maximum concentration; $\mathrm{T}_{\max }$, the time of peak concentration; $\mathrm{AUC}_{0 \rightarrow \infty}$, area under concentration curve (AUC) from time zero extrapolated to infinity; $\mathrm{V} / \mathrm{F}$, volume of distribution $/ \mathrm{F}$, where $\mathrm{F}$ is the faction of dose absorbed; $\mathrm{Cl} / \mathrm{F}$, Clearance $/ \mathrm{F}$, where $\mathrm{F}$ is the faction of dose absorbed; $\mathrm{t}_{1 / 2 \lambda z}$, terminal elimination half-life; MAT, mean absorption time; MRT, mean residual time. Data were expressed as means \pm SE. ${ }^{\text {a) }}, P<0.05$ versus control.

descriptive and comparative statistics were calculated with use of SPSS 12.0 (SPSS, Chicago, IL, USA). The significances of differences among experimental groups were determined using one-way analysis of variance (ANOVA) or the corresponding nonparametric KruskalWallis test, as required. Where significant effects were found, post-hoc analysis using the Tukey's multiple comparison test or Mann-Whitney U-test was performed, and $P<0.05$ was considered to be statistically significant.

Many essential oil components are generally recognized as safe by the Food and Drug Administration (FDA) in the USA and have been used as artificial flavors and preservatives in the manufacture of perfume and over-the-counter formulations of medicines [1]. Some essential oils have demonstrated strong antimicrobial, antifungal, anti-inflammatory and insecticidal activities $[1,7,9,16,20]$. Recently, there was extensive research on the biomedical applications in industrial animals served as antibiotic alternatives and natural insecticides $[2,14,17,28]$.

The plasma concentration-time profiles and pharmacokinetic parameters of ENFX after its oral administration with or without limonene or orange oil in rats are summarized in Fig. 1 and Table 1. Compared with the control group, the $\mathrm{C}_{\max }$ of ENFX appeared to decrease when it was given with limonene, but statistically decreased in coadministration with orange oil $(P<0.05)$. The $\mathrm{T}_{\max }$ of ENFX was delayed in the group administered

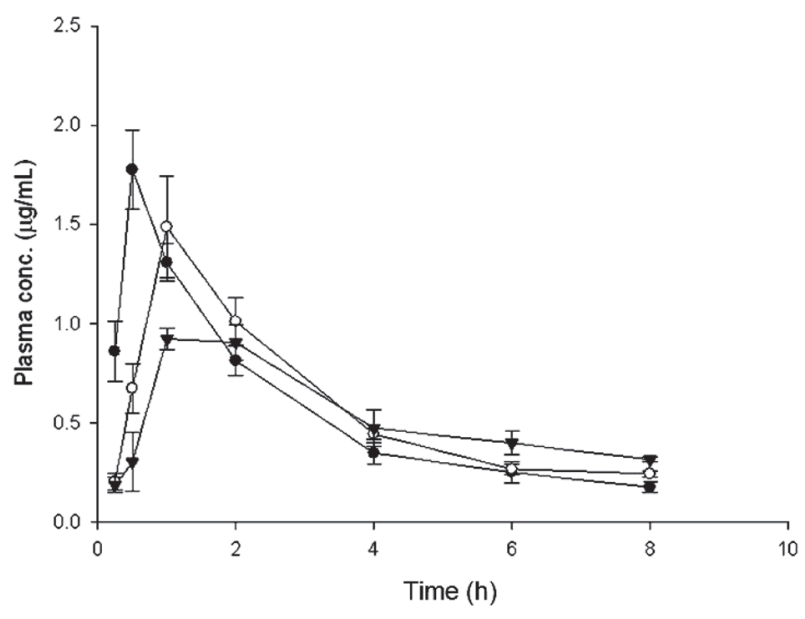

Fig. 1. Mean plasma concentrations of ENFX after a single oral administration of $10 \mathrm{mg} / \mathrm{kg}$ of ENFX with coadministration of water $(\mathbf{O})$, limonene $(\bigcirc)$ or orange oil $(\boldsymbol{\nabla})$ to rats. Data were expressed as means $\pm \mathrm{SE}$.

ENFX in combination with limonene $(P>0.05)$ and orange oil $(P<0.05)$. Similarly, the MAT of ENFX significantly increased in the group administered ENFX in combination with limonene $(P<0.05)$ and orange oil $(P<0.05)$. In addition, the elimination half-life and MRT of ENFX were also prolonged by the concomitant administration of orange oil $(P<0.05)$.

In regard to bioequivalence, test product is considered to be bioequivalent to a referenced product if the $90 \%$ $\mathrm{CI}$ for the estimated ratios for $\mathrm{AUC}$ and $\mathrm{C}_{\max }$ were within the $80-125 \%$ boundaries [25]. For the limonene + ENFX 
group, the geometric mean ratio $\left(\mu_{\text {test }} / \mu_{\text {reference }}\right)$ showed a $90 \% \mathrm{CI}$ within 0.82 to 1.11 for $\mathrm{C}_{\max }$ and 0.89 to 1.21 for AUC. The results indicated that there were no significant differences between the reference and test treatments. However, the geometric mean ratio $\left(\mu_{\text {test }} /\right.$ $\mu_{\text {reference }}$ ) for the orange oil + ENFX group showed a $90 \%$ CI within 0.45 to 0.73 for $\mathrm{C}_{\max }$ and 0.89 to 1.22 for AUC. The single oral administrations of ENFX with water or orange oil were not bioequivalent in absorption.

The presence of food in the gastrointestinal tract is known to alter the absorption of many drugs by mechanisms that include altering the rate of gastric emptying, changing gastric $\mathrm{pH}$ or enzyme activity, and binding and chelation. Moreover, oral absorption of compounds is limited by efflux transporters located in the intestine and enhanced by influx transporters that support intestinal drug absorption [3, 11, 12, 22, 23]. There appears to be an overlap in the substrate specificity between P-gp and OATP, which could lead to opposing influences on the net absorption of a shared substrate [12]. Yoshida et al. reported that limonene did not show the significant inhibitory activity on P-gp-mediated efflux of $\left[{ }^{3} \mathrm{H}\right]$ digoxin; however other terpenoids such as citronellal, $\beta$-citronellol, $\alpha$-terpinene, terpinolene, $\beta$-pinene, abietic acid, ophiobolin A, cucurbitacin I, and glycyrrhetic acid inhibited the P-gp mediated efflux of $\left[{ }^{3} \mathrm{H}\right]$ digoxin [29]. In this study, the ENFX + limonene group did not show a significant influence on the absorption of ENFX compared with the group treated with ENFX alone except for MAT. Orange oil also had no effect on the extent of oral absorption of ENFX (AUC), but did decrease the rate of absorption and elimination, resulting in a significantly lower $C_{\max }$, delayed $\mathrm{T}_{\max }$, and prolonged MAT and elimination halflife.

Oxygen heterocyclic compounds such as furanocoumarins, psoralens, and polymethoxyflavones were also found in the orange oil [13]. They have been identified not only substrates for both P-gp and OATP but also inhibitors capable of significantly decreasing the bioavailability of other substrates. In particular, fruit juices and constituents can interact with members of the OATP transporter family by reducing their activities and significantly reduced the oral bioavailability of drugs $[6$, $10,19]$.
Fluoroquinolones including ENFX are zwitterionic and may therefore be recognized by both efflux and influx drug transporters. Although we have no direct evidence regarding the mechanism of low bioavailability of ENFX when it administered with orange oil, it may be speculated that an interaction between the orange oil and ENFX at the intestinal transport mechanism level involving identified mechanisms such as P-gp and OATP may contribute to the lower absorption of ENFX.

Because ENFX is a concentration-dependent antibiotic, these significant drops in $\mathrm{C}_{\max }$ and delayed $\mathrm{T}_{\max }$ have the potential to result in clinical failures, even against highly susceptible pathogens, as well as to promote the development of antibiotic resistance due to suboptimal killing. This decrease in exposure of ENFX could result in reduced efficacy of antibacterial therapy and changes in tissue distribution and residues in veterinary animals. Therefore, ENFX in combination with orange oil as antibiotics alternatives and natural insecticides should be used carefully.

\section{References}

1. Burt, S. 2005. Int. J. Food Microb. 94: 223-253.

2. Burt, S.A., Vlielander, R., Haagsman, H.P., and Veldhuizen, E.J. 2005. J. Food. Prot. 68: 919-926.

3. Chan, L.M., Lowes, S., and Hirst, B.H. 2004. Eur. J. Pharm. Sci. 21: 25-51.

4. Dautrey, S., Felice, K., Petiet, A., Lacour, B., Carbon, C., and Farinotti, R. 1999. Br. J. Pharmacol. 127: 1728-1734.

5. Dautrey, S., Rabbaa, L., Laouari, D., Lacour, B., Carbon, C., and Farinotti, R. 1999. Antimicrob. Agents Chemother. 43: 678-680

6. Dresser, G.K., Bailey, D.G., Leake, B.F., Schwarz, U.I., Dawson, P.A., Freeman, D.J., and Kim, R.B. 2002. Clin. Pharmacol. Ther. 71: 11-20

7. Grassmann, J., Hippeli, S., Dornisch, K., Rohnert, U., Beuscher, N., and Elstner, E.F. 2000. Arzneimittelforschung 50: 135-139.

8. Hognadottir, A. and Rouseff, R.L. 2003. J. Chromatogr. A 998: 201-211.

9. Kalemba, D., Kusewicz, D., and Swiader, K. 2002. Phytother. Res. 16: 288-291.

10. Kamath, A.V., Yao, M., Zhang, Y., and Chong, S. 2005. J. Pharm. Sci. 94: 233-239.

11. Kim, R.B. 2003. Eur. J. Clin. Invest. 33: 1-5.

12. Kim, R.B., Fromm, M.F., Wandel, C., Leake, B., Wood, A.J., Roden, D.M., and Wilkinson, G.R. 1998. J. Clin. Invest. 101: 289-294.

13. Manthey, J.A. 2006. J. Agric. Food Chem. 54: 3215-3218.

14. Meyer, N.F., Erickson, G.E., Klopfenstein, T.J., Greenquist, 
M.A., Luebbe, M.K., Williams, P., and Engstrom, M.A. 2009. J. Anim. Sci. 87: 2346-2354.

15. Nouaille-Degorce, B., Veau, C., Dautrey, S., Tod, M., Laouari, D., Carbon, C., and Farinotti, R. 1998. Antimicrob. Agents Chemother. 42: 289-292.

16. Oliveira, A.C., Leal-Cardoso, J.H., Santos, C.F., Morais, S.M., and Coelho-de-Souza, A.N. 2001. Braz.J. Med. Biol. Res. 34: 1471-1474.

17. Oviedo-Rondon, E.O., Hume, M.E., Hernandez, C., and Clemente-Hernandez, S. 2006. Poult. Sci. 85: 854-860.

18. Rubinstein, E., St. Julien, L., Ramon, J., Dautrey, S., Farinotti, R., Huneau, J.F., and Carbon, C. 1994. J. Infect. Dis. 169: 218-221.

19. Satoh, H., Yamashita, F., Tsujimoto, M., Murakami, H., Koyabu, N., Ohtani, H., and Sawada, Y. 2005. Drug Metab. Dispos. 33: 518-523.

20. Schelz, Z., Molnar, J., and Hohmann, J. 2006. Fitoterapia 77: 279-285.

21. Steuera, B., Schulz, H., and Lägerb, E. 2001. Food Chem.
72: 113-117.

22. Terada, T. and Inui, K. 2004. Curr. Drug Metab. 5: 85-94.

23. Tirona, R.G. and Kim, R.B. 2002.Adv. Drug Deliv. Rev. 54 : 1343-1352.

24. Tyczkowska, K., Hedeen, K.M., Aucoin, D.P., and Aronson, A.L. 1989. J. Chromatogr. 493: 337-346.

25. U.S. Department of Health and Human Services, Food and Drug Administration, Center for Veterinary Medicine. 2006. Guidance for Industry: Bioequivalence Guidance.

26. Vancutsem, P.M., Babish, J.G., and Schwark, W.S. 1990. Cornell Vet. 80: 173-186.

27. Vancutsem, P.M. and Schwark, W.S. 1992. Epilepsy Res. 13: 59-71.

28. Yang, W.Z., Benchaar, C., Ametaj, B.N., Chaves, A.V., He, M.L., and McAllister, T.A. 2007. J. Dairy Sci. 90: 56715681.

29. Yoshida, N., Koizumi, M., Adachi, I., and Kawakami, J. 2006. Food Chem. Toxicol. 44: 2033-2039. 